http://dx.doi.org/10.12795/PH.1989.v04.i02.03

\title{
NOTAS SOBRE AFRONEGRISMOS EN DOCUMENTOS AMERICANOS DEL CARIBE EN LOS SIGLOS XVI Y XVII
}

\author{
Mariano Franco Figueroa \\ I. B. «Antonio Machado». Sevilla
}

La contribución de las distintas regiones peninsulares a la lengua de América sigue ofreciendo un campo de estudio atrayente para los lingüistas ${ }^{1}$, que, divididos en grupos diferenciados por sus posturas teóricas diversas, se centran unos en teorías poligenéticas y otros en posturas que defienden una relevante acción de sustrato. Todos coinciden en la variada aportación social de la Península en la colonización americana, tanto diatópicamente, como en sentido diastrático, que conformará la peculiar coiné léxica hispanoamericana.

Pero, al analizar las bases del español americano, en los distintos niveles de lengua, no hay que contar sólo con la emigración española. Ya Peter BoydBowman ${ }^{2}$ constataba la presencia de un grupo importante de extranjeros desde los inicios del descubrimiento del Nuevo Mundo. Franceses, italianos y portugueses, sobre todo, aparecen registrados en documentos indianos como habitantes

1 Véanse al respecto los trabajos de Juan Antonio Frago Gracia, «Materiales para la historia de la aspiración de la /-s/ implosiva en las hablas andaluzas», Revista de Lingüística Española Actual, V, 1983, págs. 153-71; «La fonética del español meridional y sus fuentes históricas», Miscelánea Sanchis Guarner, II, Valencia, 1984, págs. 131-7; «Historia del andaluz: problemática y perspectivas», en El habla andaluza. Homenaje a Zubiri, Sevilla, Colegio de Licenciados, 1985, págs. 61-73. Y los de Gregorio Salvador, contrario a las tesis andalucistas, "América y Andalucía ante el futuro de la lengua», Lengua española y lenguas de España, Barcelona, Ariel, 1987, págs. 70-88; «Discordancias dialectales en el español atlántico (1978-1981)», Estudios dialectológicos, Madrid, Paraninfo, 1982, págs. $70-8$.

2 Peter Boyd-Bowman. «La emigración española a América: 1500-1579», separata de Studia hispania in honorem Rafael Lapesa, II, Madrid, 1974, Cátedra Seminario Menéndez Pidal y Gredos, págs. 123-47. 
de la incipiente sociedad colonial que, como fruto de esta diversificación étnica, verá aumentar su caudal léxico con préstamos de sus respectivas lenguas ${ }^{3}$.

Desde que Rufino José Cuervo recogiera ciertas voces de procedencia occidental -leonesismos y portuguesismos- en sus obras ${ }^{4}$, los trabajos centrados de manera especial en los lusismos han recalcado el valor de tales términos en el conjunto del sistema lingüístico del español. Así, a los estudios de Joan Corominas ${ }^{5}$ y Gregorio Salvador ${ }^{6}$, hay que añadir la labor desarrollada por Germán de Granda ${ }^{7}$. Este autor, en la explicación de las vías de penetración de este componente al acervo español, señala un elemento social de relieve: el de la población negra de origen portugués. La importación de esclavos negros procedentes del África portuguesa, que habrían evolucionado hacia una modalidad lingüística criolla de base portuguesa, bien en el continente africano, bien en la misma metrópoli ${ }^{8}$, permite deducir con cierta lógica que, durante un tiempo variable según el grado de cohesión entre agrupaciones de hablantes africanos que determinadas condiciones sociales ofrecieran ${ }^{9}$ - , las poblaciones negras siguieron practicando su variante lingüística, convertida en vehículo de penetración de elementos léxicos lusos.

Con independencia de su consideración como medio transmisor de portuguesismos, el elemento afronegroide y su incidencia directa, tanto por su cultura y costumbres, como por su lengua aborigen, tuvieron que dejar huella en tierras americanas a juzgar por los datos demográficos que se manejan ${ }^{10}$. Sin embargo, si la población negra fue muy numerosa desde los primeros momentos, no lo fue tanto el número de términos que pasará al bagaje léxico americano. Este

3 Un estudio de los préstamos de estas lenguas en documentos americanos, comparando los resultados y la preponderancia de cada grupo, figura en mi tesis doctoral Léxico hispanoamericano de los siglos XVI y XVII en fuentes de América Central y de la Nueva España, dirigida por el Dtor. D. Juan Antonio Frago Gracia, presentada en la Universidad de Sevilla, 1988.

4 Rufino José Cuervo, Apuntaciones críticas sobre el lenguaje bogotano, novena edición, Bogotá, Instituto Caro y Cuervo, 1955; también en Obras completas I, Bogotá, 1954, págs. 1-906.

5 Joan Corominas, «Indoamericanismos léxicos. Estudios de lexicografía hispana. Occidentalismos americanos», Revista de Filología Española, VI, 1944, págs. 1-35, 139-75 y 209-54.

6 Gregorio Salvador, «Elementos constitutivos del español: lusismos», Enciclopedia Lingüística Hispánica, vol. II, Madrid, CSIC, 1967, págs. 239-61.

7 Germán de Granda Gutiérrez, Estudios lingüisticos hispánicos, afrohispánicos y criollos, Madrid, Gredos, 1978; «Contactos sociohistóricos y préstamos léxicos. Lusismos en el español de Paraguay», en Revista de Lingüística Española Actual, II, 1980, págs. 347-73.

8 Sabido es que en la zona del Algarve portugués, la población negra en el siglo XVI era mayoritaria. Cuentan que en Lisboa, hacia la mitad del siglo, se albergaban unos diez mil esclavos, la décima parte de su población total, según datos de Manuel Álvarez Nazario, Elemento afronegroide en el español de Puerto Rico. Contribución al estudio del negro en América, San Juan de Puerto Rico, Instituto de Cultura Puertorriqueña, 1961, págs. 24-5.

9 Germán de Granda Gutiérrez, Estudios lingüísticos hispánicos, afrohispánicos y criollos, Madrid, Gredos, 1978, pág. 210.

10 Véanse como ejemplos la citada obra de Álvarez Nazario, la de Gonzalo Aguirre Beltrán, La población negra de México. Estudio etnohistórico, México, Fondo de Cultura Económica, 1946, corregida y aumentada en 1972, reimpresa en 1984; la de Miguel Acosta Saignes, Vida de los esclavos negros en Venezuela, Caracas, 1967; y la de Nicolás del Castillo Mathieu, Esclavos negros en Cartagena y sus aportes léxicos, México, 1982. 
hecho contradictorio tiene explicación. La relativa escasez de elementos derivados de las lenguas africanas, como comenta G. de Granda ${ }^{11}$, es consecuencia de un proceso de filtrado de las características fonéticas, morfosintácticas y léxicas aborígenes antes de llegar al estadio castellano mediante el paso previo y la desaparición mayoritaria de estas modalidades a través de la fase criolla, primero de matriz portuguesa y luego castellanizada. No hay que olvidar tampoco el condicionante sociológico de una sociedad esclavista, con claro sentimiento de superioridad cultural y racial, que actuaría como factor restrictivo en la adopción de préstamos indígenas ${ }^{12}$, toda vez que el negro no era sino una pieza -en voz de la época- de trabajo dentro del organigrama social ${ }^{13}$.

La pervivencia de las aportaciones del africano al español ultramarino ha sido reflejada en algunos estudios hispánicos que pueden considerarse básicos en el inicio de esta tarea investigadora. Después del Glosario de afronegrismos de Fernando de Ortiz ${ }^{14}$, el habla de los negros en América recibe un tratamiento significativo en la obra de Manuel Álvarez Nazario, El elemento afronegroide en el españo de Puerto Rico ${ }^{15}$. Una consideración más reciente, aunque menos amplia, aparece en «Elementos africanos en el español de Cuba», de Humberto López Morales ${ }^{16}$. Pero los trabajos más constantes y precisos de deben al citado G. de Granda ${ }^{17}$ que, con criterios etnográficos y nuevos planteamientos sociológicos, da luz a algunas interrogantes sobre las posibles influencias lingüísticas africanas en el español del Nuevo Mundo y propone líneas nuevas de investigación que aumenten, por una parte, la escasa bibliografía al respecto, y, por otra, el rigor científico de los estudiosos, de manera que constituyan una garantía contra los errores inevitables de las obras realizadas por aficionados que carecen de una precisa formación lingüística general ${ }^{18}$.

Bastaría estas últimas opiniones para disuadirnos de la exposición que nos proponemos. Con todo, dado que la lista de términos recogida incluye una proporción abrumadora de gentilicios y que éstos pueden servir de pequeña muestra documental sobre la distribución de los esclavos negros en Hispanoamérica durante los primeros siglos coloniales ${ }^{19}$, nos hemos arriesgado a recoger un lexicón

11 Germán de Granda, Estudios lingüísticos, op. cit., pág. 209.

12 Hugo Mejías, Préstamos de lenguas indígenas en el español americano del Siglo XVII, México, 1980, pág. 20 .

13 Quizás este hecho dé razón de la mayor extensión y pervivencia de lenguas africanas en niveles populares y en las zonas donde se ha mantenido una cohesión del grupo por razones específicas, como hoy en día en Cuba, por ejemplo.

14 Fernando de Ortiz, Glosario de afronegrismos, La Habana, 1924.

15 Véase nota 8.

16 En Estudio sobre el español de Cuba, Madrid, Anaya, 1971, págs. 62-71.

17 Véanse las obras citadas en la nota 7, que recoge los trabajos más importantes.

18 Germán de Granda, Estudios Lingüísticos, op. cit., pág. 187.

19 Germán de Granda, «Onomástica y procedencia africana de esclavos negros en las minas del sur de la Gobernación de Popayán (S. XVIII)», Revista Española de Antropología Americana, VI, 1971, págs. 381-422. También en los artículos de G. de Granda, «Materiales para el estudio sociohistórico de los elementos lingüísticos afroamericanos en el área hispánica», Thesaurus, XXIII, 1968, págs. 547-73. Más concretamente, «Materiales complementarios para el estudio sociohistórico de los 
de voces africanas procedentes de documentos coloniales de la zona caribeña ${ }^{20}$ que confirmen los grupos y culturas africanas incorporadas a la emigración europea.

El inventario obtenido lo constituye 22 africanismos. De su estudio podemos colegir las siguientes conclusiones:

1) El fondo léxico está conformado por voces que designan el origen tribal de los esclavos. Sólo dos términos hacen referencia a otros aspectos de la realidad: bezar y ñame. El primero, de posible etimología norteafricana, se aplica a unas 'piedras de uso medicinal, como contraveneno' ${ }^{21}$. La segunda de estas voces, de etimología discutida ${ }^{22}$, designa a una 'planta comestible americana', de origen claramente africano para algunos, como el cronista Gonzalo de Oviedo, y que, por la temprana documentación que ofrece G. Friederici, su nuevo empleo estaría en relación con la larga convivencia entre los negros bozales y su lenguaje criollo con el lenguaje de los marineros y conquistadores españoles, quienes, por la necesidad de nominación que acarrea la nueva realidad americana, tomarán el préstamo africano.

2) El grupo formado por los veinte términos restantes muestra dos aspectos de clara relación lingüística: la onomástica ${ }^{23}$ y los gentilicios.

Los esquemas onomásticos que presentamos en nuestras citas documentales responden a las estructuras que damos a continuación:

a) nombre cristiano + otra marca de identificación no onomástica. Por ejemplo: «un negro llamado Antonio, de tierra angola».

b) nombre cristiano + gentilicio de procedencia africana. En esta estructura onomástica, encontramos dos casos: en el primero, aparece el gentilicio postpuesto al nombre cristiano con clara función aposicional; ejemplo: «una esclava negra llamada Antonia, engola». En el segundo, la designación de la procedencia africana se muestra como elemento antroponímico: «dos piezas de esclavos llamados Hernando çape, y el otro Gregorio, bran».

c) gentilicio africano. Ejemplo: «se armaron muchos negros carabalíes para matar a su amo».

En resumen, de los contextos registrados, 14 responden al esquema a). El número de citas que se corresponde con la estructura b) se distribuye de la siguiente

elementos afroamericanos en el área hispánica (I América)», Thesaurus, XXVI, 1971, págs. 118-33, y «Materiales complementarios para el estudio sociohistórico de los elementos lingüísticos afroamericanos en el área hispánica (II África)», Thesaurus, XXVI, 1971, págs. 400-22. En ellos se insiste en la necesidad de un mayor expurgo documental que contribuya a un mejor conocimiento del tema.

20 Salvo los contextos de las voces carabalí y guinea, que aparecen en documentos mejicanos, nos hemos ceñido a la zona del Caribe. Al final del trabajo se exponen las fuentes estudiadas.

21 El mundo de la magia, estrechamente relacionado con la salud, lógicamente pervive con mayor fuerza en la vida de estos esclavos, ligados en su interior a costumbres y formas de vida ahora depuradas ante la nueva realidad. La obra de Alonso de Sandoval, Tractatus de instauranda aethipum salute, de 1627, publicada ahora con el título de Un tratado sobre la esclavitud, con introducción y notas a cargo de Enriqueta Vila Vilar, Madrid, Alianza, 1987, ofrece una rica y variada descripción de los ritos y ceremonias de estas tribus. Véase también la obra de Fernando de Ortiz, Hampa afrocubana: los negros brujos, Madrid, 1914.

22 Humberto López Morales, op. cit., pág. 70.

23 Véase Manuel Álvarez Nazario, Elemento afronegroide, obra citada, págs.187-91. 
forma: 14 ejemplos para el primer caso y 4 ejemplos para el segundo. Del esquema c) mostramos 2 contextos.

Coinciden nuestros resultados con los datos que ofrece G. de Granda para la región minera de Popayán en el siglo XVIII ${ }^{24}$. Así, de los esquemas que propone este autor, será el de «nombre cristiano sin otro elemento antroponímico, aunque usando otras marcas de identificación no onomástica», el que dará una cifra más alta, con abrumadora mayoría sobre el resto de los esquemas. Del mismo modo, la individualización del esclavo que sigue al nombre cristiano se realiza a través de las expresiones: de nación, de tierra o natural de, que, como ya señalara Gonzalo de Aguirre Beltrán ${ }^{25}$, daban idea del origen geográfico del mismo, al tiempo que significaban una característica cultural, como el no pertenecer al mundo islámico, para el que se utiliza siempre el término casta. El esquema c) viene a confirmar el viejo procedimiento onomástico en el español general de dar como apodo una característica geográfica, cultural o física, que luego adquiere el valor de apellido, como lo corrobora su posterior uso en los países hispanoamericanos.

En cuanto a los gentilicios, y como pequeña aportación para el rastreo de las agrupaciones étnicas y lingüísticas que pasaron a América y de la mayor o menor preponderancia de cada una, aun cuando todos conocen la dificultad que encierran las denominaciones africanas para averiguar el punto de origen de los esclavos y las rectificaciones a que se ven sometidos estos resultados ${ }^{26}$, hay que recalcar la mayor presencia del grupo sudanés, donde se encuentran los inobedientes jelofes, los berbesíes, biafaras, nalúes, mandingas, biochos y zapes; de cultura mixta, bantú-sudanesa, los carabalíes y los branes. El grupo bantú presenta al pueblo de los ambos y las determinaciones generales de guinea, congo, angola y mozambique. En conjunto, el grupo de gentilicios mayoritario se centra geográficamente en las zonas costeras del golfo de Guinea y el Sudán Occidental, mientras que la zona del Congo, Angola o el área de Mozambique están menos representadas ${ }^{27}$.

Finalmente, citamos a continuación la nómina de afronegrismos con sus correspondientes contextos. No pretendemos elaborar este vocabulario de manera

24 Sólo hemos recogido los casos en los que aparecen gentilicios africanos. Para una completa visión de posibles esquemas onomásticos, véase G. de Granda, en su artículo citado sobre onomástica, pág. 385 .

25 Gonzalo Aguirre Beltrán, op. cit., págs. 105 y 160-1.

26 Estas dificultades aparecen ya en la citada obra de Aguirre, pág. 100, y en la de M. Álvarez Nazario, El elemento afronegroide, op. cit., pág. 17-8, pues el punto de origen declarado en los documentos eran casi siempre el de los puertos de la costa donde los embarcaban y no de sus tribus o lugares de origen, a veces muy diferentes y apartados entre sí. El propio Alonso de Sandoval confirmaba esta circunstancia cuando escribe: «los negros de la isla de S. Thome (que es puerto de donde salen navios para el rescate de los negros que comúnmente dezimos venir de $\mathrm{S}$. Thome, y no son sino de la tierra firme, Reinos y puertos que hemos dicho donde los Españoles van a su rescate) son de menor ley que los [...] de los Ríos de Guinea», pág. 139, de la citada obra.

27 Germán de Granda en su artículo citado sobre la onomástica de los esclavos de Popayán ofrece unos resultados siguiendo la clasificación de Melville Herskowits, con una zona de Guinea, otra del Congo y una tercera área que comprendería el Sudán Occidental. 
extensiva, sino mostrar contextos históricos donde observar la palabra aborigen. En la presentación del material, hemos adoptado el siguiente orden: después de la voz de entrada, ofrecemos el significado, a excepción de los gentilicios en los que se deduce de los datos aportados en el artículo; luego, la datación geográfica y cronológica de la documentación, comenzando por la abreviación de las fuentes, número de página y año. A continuación damos entre paréntesis el contexto de cada término. Dos barras separan todo lo anterior de las referencias bibliográficas que se consultan para cada voz en los distintos artículos.

\section{LEXICÓN DE AFRONEGRISMOS}

Anchico: Difícil localización, quizás del interior de África oriental, entre el Congo y Zaire, grupo bantú. PRH I (Habana, Cuba), pág. 382, 1585 («Catalina, de nación anchica»). // DCECH y DRAE no registran; Sandoval, pág. 66, registra a los angicos en un reino cercano al angolés; Aguirre, págs. 100 y 138-9, indica que en Cuba y otros países hispanoamericanos se les conoce con el nombre de anchico y enchica.

Angola: PRH I (Habana, Cuba), pág. 148, 1579 («una esclava negra llamada Antonia, engola»); PRH II (Habana, Cuba), pág. 52, 1586 («Juan, de nación angola»); ídem, pág. 83 («Una negra nombrada Esperanza, de tierra angola»); PVC (Caracas, Ven.), pág. 5, 1595 («un negro llamado Antonio, de tierra angola»). // DCECH y DRAE no registran; Aguirre, pág. 141; Acosta, pág. 132; Álvarez Nazario, págs. 71-2, 254-5, indicando el uso como apellido desde 1606 en Santo Domingo; G. de Granda, Estudios afrohispánicos, pág. 275; Boyd-Bowman, Léxico S. XVI, documenta desde 1562, Puebla.

Bañol: Zona de Guinea, grupo sudanés. PRH II (Habana, Cuba), pág. 31, 1586 («Catalina, bañol»). // DCECH y DRAE no registran; Sandoval, pág. 63, registra banun; Aguirre, págs. 101 y 117; Acosta, pág. 132.

Berbesí: De difícil localización, quizás entre Cabo Verde y Senegal, grupo sudanés. PRH I (Habana, Cuba), pág. 130, 1579 («Juan Berbeçí e Duarte e otros negros»); ídem, 251, 1579 («dos esclavos negros llamados Juan Berbesí y Catalina). // DCECH y DRAE no registran; Aguirre, pág. 100, confundidos a veces con los jalofes.

Bezar: 'Piedra o cálculo que suele encontrarse en las vías digestivas y urinarias de algunos mamíferos, y que se consideran de uso medicinal, como contraveneno'. RG (Ven.), pág. 155, 1579 («se sacan piedras del buche que se llaman bezares, y que se tienen [...] por contra-yerba»). // DCECH, s. v. bezoar, del árabe africano bezuwâr, documenta en 1578; DRAE; Aut.; Terreros; Moliner; Boyd-Bowman, Léxico s. XVI, ídem documentación. 
Biafara: Zona de Guinea, perteneciente al grupo sudanés. PRH I, (Habana, Cuba), pág. 91, 1579 («esclavo negro llamado Cristóbal, viafra»); ídem, II, pág. 35, 1587 («Francisca, de nación biafara»); ídem, pág. 213, 1586 («un negro aserrador nombrado Juan, biafara»); ídem, 291, 1587 («esclava negra [...] llamada Isabel, de tierra biafara»). // DCECH y DRAE no registran; Aguirre, págs. 136-7; Álvarez Nazario, pág. 55, indica que vive hoy como apellido en Cuba, Puerto Rico y Santo Domingo, donde se documenta desde 1606, en Colombia se acentúa biáfara; Boyd-Bowman, Léxico s. XVI, documenta en 1554, Pueblo, s. v. biáfara.

Biocho: Zona guineana, grupo sudanés. PRH I (Habana, Cuba), pág. 379, 1585 («esclava negra nombrada Catalina, de naçion biocho»). // DCECH y DRAE no registran; Aguirre, págs. 101 y 108, con la indicación de que tenían fama de ser muy serviciales desde su entrada en la Nueva España con los nombres de biochos viohos o viojo; Boyd-Bowman, Léxico s. XVI, ídem documentación.

Bran, braní: Relacionado con el grupo carabalí, del puerto africano Calabar, cultura bantú-sudanesa. PRH I (Habana, Cuba), pág. 56, 1579 («dos piezas de esclavos llamados Hernando çape, y el otro Gregorio bran»); ídem, pág. 189 («un esclavo [...] nombrado Duarte, braní»); PRH II (Habana, Cuba), pág. 122, 1586 («Françisco, de nación brant »). // DCECH y DRAE no registran; Aguirre, pág. 128; Acosta, pág. 133; Álvarez Nazario, pág. 65, usado como apellido desde 1606; Boyd-Bowman, Léxico s. XVI, ídem documentación.

Cangala: Norte de Sierra Leona, grupo sudanés. PRH I (Habana, Cuba), pág. 249, 1579 («Pero, cangala»). // DCECH y DRAE no registran; Aguirre, pág. 122, registra cangá, contracción de cangará, pueblo mandé de Sierra Leona.

Carabalí: 'Negro de Carabalí, región africana del este de Nigeria, que era poco estimado por su carácter indómito‘, grupo bantú-sudanés. SN I (Mej.), pág. 232, 1678 («se armaron muchos negros carabaries para matar al amo»). // DCECH no registra; DRAE; Moliner; DGA, 'negro de África', 'nombre vulgar de una variedad de jutía' (Cuba), 'nombre de varias clases de árboles (Venezuela); Neves, ídem DGA; Pichardo; Aguirre, págs. 134-5; Acosta, pág. 133; Álvarez Nazario, págs. 64-5 y 256, usado como apelativo desde los comienzos coloniales, hoy conservado en el Caribe, Colombia y Ecuador.

Cemba: Difícil localización, quizás bantú del sur de Zaire. PRH I (Habana, Cuba), pág. 217, 1579 («María, çemba»). // DCECH y DRAE no registran; Aguirre, pág. 140, cita la voz bamba como pueblo del sur de Zaire que pudiera representar a la palabra que estudiamos; Acosta, pág. 133, registra bembo con el sentido de bamba. Podría ser variante de embo, citado más abajo.

Congo: PRH I (Habana, Cuba), pág. 28, 1579 («esclavo negro llamado Antón de Lobera, de nación congo»). // DCECH no registra; DRAE; Aguirre, págs. 137-9; Acosta, pág. 133; Álvarez Nazario, págs. 69-70 y 257, usado como apellido desde 1826, registra también el cambio de género conga; G. de Gran- 
da, Estudios afrohispánicos, pág. 389; Boyd-Bowman, Léxico s. XVI, ídem documentación.

Embo: Posible origen bantú. PRH II (Habana, Cuba), pág. 23, 1586 («una esclava negra llamada María, de naçión enbo»). // No registran las obras consultadas, salvo Sandoval, pág. 139 y Aguirre, págs. 136-7, con una incidencia mínima en la trata.

Guinea: APM I (Mej.), pág. 181, 1527 («esclavo negro, natural de Guinea»). // DCECH no registra; DRAE; Aguirre, págs. 102 y 105; Acosta, pág. 135; Álvarez Nazario, págs. 206-9, con referencia al uso para designar al plátano de Guinea, documentado entre el siglo XVIII y XIX, en Cuba y Puerto Rico; Boyd-Bowman, Léxico s. XVI, documenta desde 1572, Perú ${ }^{28}$.

Jelofa: Zona senegalesa, grupo sudanés. PRH II (Habana, Cuba), pág. 321, 1587 («poder [...] para vender [...] sus esclavas negras de tierra jalofa»). // DCECH y DRAE no registran; Aguirre, pág. 116; Acosta, pág. 135; Álvarez Nazario, págs. 51 y 257-8, documenta el término desde 1413, en Sevilla; G. de Granda, Estudios afrohispánicos, pág. 303; Boyd-Bowman, Léxico s. XVI, ídem documentación.

Mana congo: Designación general de los habitantes de las riberas del río Zaire o Congo, grupo bantú. PRH I (Habana, Cuba), pág. 213, 1579 («Pablo, de nación mana congo»). // DCECH y DRAE no registran; Aguirre, págs. 101, 137; Álvarez Nazario, págs. 212-3, comenta la etimología de manicongo, nombre de un rey según Sandoval.

Mandinga: Procedente de Cabo Verde y de las zonas senegalesas y de Sierra Leona, grupo sudanés. PRH II (Habana, Cuba), pág. 399, 1587 («un negro llamado Hernando, de nación mandinga»). // DCECH documenta en el último tercio del s. XVI, hoy en Centroamérica, según Malaret, y extendido su uso hasta Argentina, con el significado de 'diablo', 'superstición', en Canarias significa 'vísceras', 'cobarde', en Murcia, 'hombre flojo'; DRAE, ídem Corominas, y añade 'muchacho travieso' (Argentina); Moliner, ídem DRAE y Corominas; Aguirre, págs. 107 y 117; Acosta, págs. 136-7; Álvarez Nazario, págs. 51 y 258; G. de Granda, Estudios afrohispánicos, págs. 303 y 309; Boyd-Bowman, Léxico s. XVI, documenta desde 1556, Puebla.

Mozambique: PRH I (Habana, Cuba), pág. 180, 1579 («un esclavo negro llamado Hernando, moçanbique»). // DCECH y DRAE no registran; Aguirre, pág. 145; Álvarez Nazario, págs. 72-4 y 259-60, hoy como apellido en Méjico; Boyd-Bowman, Léxico $s$. XVI, ídem documentación.

28 El uso de guinea como forma elíptica para designar al 'plátano' figura en nuestra tesis doctoral antes mencionada, con documentos de Caracas. La forma guinea se registra en el diccionario de Esteban de Terreros y Pando, con la imputación de América, y en las obras lexicográficas de Francisco de Santamaría, Neves y Morínigo, referida a las zonas de América Central, Méjico y el Caribe. 
Mozambo, mosambo: Zona del Congo, grupo bantú. PRH I (Habana, Cuba), pág. 190, 1579 («pieças desclavos llamados Fransisco moçambo y Duarte, bran»). // DCECH y DRAE no registran; Aguirre, pág. 138, registra mossanga.

Nalú: Guinea Portuguesa, grupo sudanés. PRH I (Habana, Cuba), pág. 130, 1579 ( Ocho ducados que debo a Marcos, negro del rrey, nalú»). // DCECH y DRAE no registran; Sandoval, págs. 64 y 138; Aguirre, pág. 118; BoydBowman, Léxico $s$. XVI, ídem documentación.

Name: 'Planta discoreácea, de raíz tuberculosa comestible‘. RG (Ven.), pag. 154, 1579 («caírdes, que es a modo de ñames»). // DCECH, palabra africana, documenta en Colón: DRAE, voz del Congo; Alcedo; Terreros, 'raíces de que se hace el cazabe'; Friederici documenta en 1492, Navarrete; Moliner, usual; DGA añade los significados 'pie grande y deforme', 'torpe, inhábil', señalando siempre la procedencia africana; Malaret, 'cosa grande y deforme' (Colombia, Puerto Rico, Santo Domingo, Venezuela), 'persona torpe‘ (Cuba); Morínigo (América Central, Antillas, Colombia, Méjico, Venezuela), 'pie grande y deforme' (Antillas, Colombia, Venezuela); Neves (América), ídem Malaret; Alvarado I, pág. 267, trae una cita de Oviedo que no deja lugar a dudas sobre la etimología de esta voz, que, a veces, se pensaba indígena: «Ñame es una fructa extrangera e no natural de aquestas Indias, la qual se ha traydo a esta nuestra Isla Española [...] e vino con esta mala casta de negros»; R. Lapesa, Historia de la Lengua Española, pág. 377, registra esta voz, al tiempo que recuerda la inseguridad etimológica de muchas de estas; Álvarez Nazario, Castellano de los conquistadores, pág. 19, y en Elemento afronegroide, págs. 219-22, ofrece un origen sudanés-bantú; López Morales, Español de Cuba, pág. 92, 'raíz del chayote'.

Zape: Zona de Sierra Leona, grupo sudanés, relacionado con los mandingas. PRH I (Habana, Cuba), pág. 32, 1579 («un esclavo negro llamado Diego, çape»); ídem, pág. 46 («Antón, herrero, de naçión çepe»); PRH II (Habana, Cuba), pág. 394, 1587 («Pero, bran, Costança, çape»). // DCECH y DRAE no registran; Aguirre, págs. 101, 119 y 121; Acosta, págs. 139-40, registra sape; Boyd-Bowman, Léxico $s$. XVI, ídem documentación.

\section{FUENTES}

APM I: Índice y Extracto de los Protocolos del Archivo de Notarías de México, D. F. Tomo I (1524-1528). Agustín Millares Carlo y José Ignacio Mantecón, Colegio de México, 1945.

PRH I: Índice y extractos del Archivo de Protocolos de La Habana. Tomo I (1578-1585). Ma Teresa de Rojas, La Habana, Imprenta Úcar, García y Cía, 1947. 
PRH II: Índice y extractos del Archivo de Protocolos de La Habana. Tomo II (1586-1587). M. Teresa de Rojas, La Habana, Imprenta Úcar, García y Cía, 1950.

PVC: Los primeros vecinos de Caracas. Manuel Pinto C., edición del Cuatricentenario de Caracas, Caracas, Comité de Obras Culturales, Talleres Italgráfica, 1966.

RG: Relaciones geográficas de Venezuela. Antonio Arellano Moreno, Fuentes para la Historia Colonial de Venezuela, Earacas, Biblioteca de la Academia Nacional de la Historia, 1964.

SN I: Diario de sucesos notables. Tomo I (1565-1703). Antonio Robles, México, Ed. Porrúa, S. A., 1946.

\section{ABREVIATURAS BIBLIOGRÁFICAS}

ACOSTA: Miguel Acosta Saignes, Vida de los esclavos negros en Venezuela, Caracas, 1967.

AGUIRRE: Gonzalo Aguirre Beltrán: La población negra de México. Estudio etnohistórico, México, Fondo de Cultura Económica, 1946, corregida y aumentada en 1972, reimpresa en 1984.

ALCEDO: Alcedo, Antonio de: Diccionario geográfico-histórico de las Indias Occidentales o América. Tomos I, II, III y IV [Biblioteca de Autores Españoles, tomos CCV, CCVI, CCVII Y CCVIII, impreso en Madrid en 1786-1789], reimpreso en Madrid, Atias, 1967, edición de Ciriaco Pérez-Bustamante. Vocabulario de las voces provinciales de América, tomo IV, págs. 559 y ss.

ALVARADO I, II, III: Alvarado, Lisandro: Obras Completas: Tomo I: Glosario de voces indígenas de Venezuela. Caracas, Ministerio de Educación y Dirección de Cultura y BA, 1953. Tomo II: Glosarios del bajo español en Venezuela. 1. parte: «Acepciones especiales». Caracas, ídem, 1954. Tomo III: Glosarios del bajo español en Venezuela. 2.a parte: "Neologismos y arcaísmos. Otros escritos conexos con ellos». Caracas, ídem, 1955.

ALVAREZ NAZARIO: Manuel Álvarez Nazario: Castellano de los conquistadores: «El castellano de los conquistadores y primitivos vecinos españoles de Puerto Rico», en Revista del Instituto de Cultura Puertorriqueña, San Juan, 1978, año XXI. n. 81, págs. 13-9.

- : El elemento afronegroide en el español de Puerto Rico. Contribución al estudio del negro en América. San Juan de Puerto Rico, Instituto de Cultura Puertorriqueña, 1974.

AUT: Diccionario de Autoridades, tomo I, A-C, II, D-Ñ, III, O-Z, Madrid, Gredos, 1976, 3. reimpresión. 
BOYD-BOWMAN: Léxico s. XVI= Boyd Bowman, Peter: Léxico hispanoamericano del siglo XVI, London, Támesis Books Limited, 1971. Publicado en Madrid por Ediciones Castilla, 1972.

DCECH: Joan Corominas y J. Antonio Pascual: Diccionario Crítico Etimológico Castellano e Hispánico, vol. I, A-Ca, II, CE-F, III, G-MA, IV, ME-RE, V, RI-X, Madrid, Gredos, 1980-1983. Para las voces con 'y', y 'z', se utiliza el Diccionario Crítico Etimológico de la Lengua Castellana, de J. Corominas, de 1955.

DGA: Francisco J. Santamaría: Diccionario general de americanismos, 3 vols., México, 1942.

DRAE: Real Academia Española; Diccionario de la Lengua Española, Tomo I, A-Guzpatarra, II, H-Zuzón, Madrid, Espasa Calpe, 1984.

FRIEDERICI: Friederici, Georg: Amerikanistisches Wörterbuch und Hislfswörterbuch für den Amerikanisten, Hamburg, 1960.

GRANDA: Granda, Germán de: Estudios afrohispánicos = Estudios lingüísticos hispánicos, afrohispánicos y criollos. Madrid, Gredos, 1978.

LAPESA: Rafael Lapesa: Historia de la lengua española, edición corregida, Madrid, 1972.

LÓPEZ MORALES: Español de Cuba = López Morales, Humberto: El estudio sobre el español de Cuba. Madrid, Las Américas, 1971.

MALARET, Augusto: Diccionario de americanismos. Buenos Aires, 1946.

MOLINER: María Moliner: Diccionario de uso del español, tomo I, A-G, tomo II, H-z, Madrid, Gredos, 1982.

MORÍNIGO: Morinigo, Marcos: Diccionario manual de americanismos. Buenos Aires, 1966.

NEVES: Neves, Alfredo N.: Diccionario de americanismos. Buenos Aires, ed. Sopena, 1973.

PICHARDO: Pichardo, Esteban: Diccionario provincial casi razonado de voces y frases urbanas. La Habana, Imprenta El Trabajo, 1875, 4. ed. (reeditado en La Habana, 1976).

SANDOVAL: Alonso de Sandoval: Un tratado sobre la esclavitud (Tractatus de instauranda aethiopum salute), edición de Enriqueta Vila Vilar, Madrid, Alianza, 1987.

TERREROS: Terreros y Pando, Esteban de: Diccionario Castellano, Tomo I, AD, II, E-O, III, P-Z, IV, Correspondencias, Madrid, ed. facsímil de Arcos Libros S.A., 1987. 
